\title{
A New Procedure for the Synthesis of Polyethylene Glycol-Protein Adducts; Effects on Function, Receptor Recognition, and Clearance of Superoxide Dismutase, Lactoferrin, and $\alpha_{2}$-Macroglobulin
}

\author{
Charles O. Beauchamp,* Steven L. Gonias, $\dagger$ David P. Menapace,* and \\ SAlvatore V. Pizzo' ${ }^{-1}$ \\ *The Department of Medicine, University of Michigan and The Ann Arbor Veterans Administration Hospital, \\ Ann Arbor, Michigan 48105, and the †Departments of Pathology and Biochemistry, \\ Duke University Medical Center, Durham, North Carolina 27710
}

Received July 28, 1982

\begin{abstract}
A new, simplified technique for the synthesis of polyethylene glycol (PEG) derivatives of proteins utilizing 1,1'-carbonyldiimidazole for PEG activation, is described. PEG derivatives of superoxide dismutase, $\alpha_{2}$-macroglobulin, $\alpha_{2}$-macroglobulin-trypsin, and lactoferrin were prepared and studied. Superoxide dismutase coupled to PEG preserved $95 \%$ of its original activity while its plasma half-life increased from $3.5 \mathrm{~min}$ to 9 or more hours depending on the PEG derivative studied. PEG-derivatized $\alpha_{2}$-macroglobulin showed decreased protease binding activity but PEG derivatives of preformed $\alpha_{2}$-macroglobulin-trypsin demonstrated no loss of activity. The plasma clearance of PEG- $\alpha_{2}$-macroglobulin-trypsin was prolonged significantly compared to native $\alpha_{2}$-macroglobulin-trypsin, particularly when a high-molecular-weight PEG was coupled to the protease inhibitor complex. The plasma clearance half-life of lactoferrin was increased 5to 20 -fold by this modification. Trinitrobenzenesulfonic acid titration studies demonstrated that $\epsilon$-amino groups of lysine residues are modified by the coupling of carbonyldiimidazole-activated PEG to proteins.

KEY WORDS: polyethylene glycol-modified proteins; superoxide dismutase; lactoferrin; $\alpha_{2^{-}}$ macroglobulin.
\end{abstract}

The hydroxyl groups of monomethoxypolyethylene glycols ( $\mathrm{HO}\left(-\mathrm{CH}_{2}-\mathrm{CH}_{2}-\mathrm{O}-\right)_{n}$ $\mathrm{CH}_{3}$ ) may be activated by cyanuric chloride and several other reagents and then coupled to lysine $c$-amino groups of proteins $(1-5)$. Polyethylene glycol-protein adducts demonstrate increased blood circulation time and decreased antigenicity and immunogenicity as compared to the unmodified proteins $(1,6-$ 12). Derivatized proteins, however, often demonstrate a marked loss of activity $(8,10)$.

$1,1^{\prime}$-Carbonyldiimidazole reacts with the hydroxyl groups on agarose to produce a derivative that reacts with nucleophiles (13). In the present manuscript a simple procedure is described for activating polyethylene glycol with this reagent. Reactions with monofunc-

\footnotetext{
${ }^{1}$ To whom all correspondence should be addressed.
}

tional (PEG-2 and PEG-5), ${ }^{2}$ bifunctional (PEG-4), and tetrafunctional (PEG-20) polymers containing one, two, and four hydroxyl groups, respectively, are compared. ${ }^{3}$ Polyethylene glycols activated with this reagent couple to lysine residues as with other activated. polyethylene glycols.

\footnotetext{
${ }^{2}$ Abbreviations used: PEG, polyethylene glycol; SOD. superoxide dismutase; $\alpha_{2} \mathbf{M}, \alpha_{2}$-macroglobulin; BAPNA, $N^{\alpha}$-benzoyl-DL-arginine-p-nitroanilide-HCl; TNBS, 2.4,6trinitrobenzenesulfonic acid.

${ }^{3}$ The monofunctional polyethylene glycols, PEG-2 and PEG-5, each have one of their hydroxyl groups replaced by a methoxy group. The bifunctional polyethylene glycol. PEG-4, has two free hydroxyl groups. PEG-20, as synthesized by the manufacturer has four free hydroxyl groups (Sigma Chemical Co., Technical Services Division). The number designations for PEG species indicate the average molecular weight of the product.
} 
The proteins derivatized with the activated polyethylene glycols include bovine liver copper-zinc superoxide dismutase, human plasma $\alpha_{2}$-macroglobulin complexed with trypsin, and human milk lactoferrin. These proteins are representative of three mechanisms of plasma clearance. Superoxide dismutase, $M_{\mathrm{r}}=31,200$, catalyzes the disproportionation of $\mathrm{O}_{2}^{-}$(14). Clearance from the mammalian circulation results from passive diffusion of the relatively small protein through the renal glomeruli (15). Lactoferrin is an iron-binding protein found in the granules of neutrophils which may play an important role in tissue injury mediated by phagocytes (16). It is rapidly cleared from the circulation by hepatocytes as a result of carbohydrate recognition (17). $\alpha_{2}$-Macroglobulin is a high-molecular-weight plasma protease inhibitor (18). Following reaction with a protease, the complex is recognized by receptors in the reticuloendothelial system and rapid clearance occurs (19). The receptor recognition site is present on the inhibitor and most likely involves a sequence of amino acids which either becomes exposed or assumes an appropriate conformation after reaction with protease.

The clearance rates of the native and polyethylene glycol-derivatized forms of these proteins are compared in mice. The results of in vitro activity experiments are also presented. Using published data and these studies, a comparison is made of some of the advantages and disadvantages of the cyanuric chloride and 1,1'-carbonyldiimidazole procedures for synthesis and polyethylene glycolprotein derivatives.

\section{MATERIALS AND METHODS}

Materials. Bovine serum albumin, trypsin, BAPNA, 1, 1'-carbonyldiimidazole, TNBS, $p$ nitrophenyl- $p^{\prime}$-guanidinobenzoate- $\mathrm{HCl}$, cytochrome $c$ type IV and SBTI were obtained from Sigma. Trypsin, purchased from Worthington, was $70 \%$ active by active-site titra- tion with $p$-nitrophenyl- $p^{\prime}$-guanidinobenzoate- $\mathrm{HCl}$ (20). Burdick-Jackson ultrapure dioxane was obtained from Anspec, Ann Arbor, Michigan; lactoperoxidase bound to Sepharose-4B from P-L Biochemicals; ${ }^{125}$ I for protein iodination from New England $\mathrm{Nu}$. clear; DE-52 from Whatman; electrophoresis reagents from Bio-Rad; and ultrapure ammonium sulfate from Schwartz/Mann. Spectrapor dialysis tubing was obtained from Fisher. PEG-4 (Carbowax 4000) was purchased from Fisher, PEG-2 and PEG-5 from Polyscience, and PEG-20 from Sigma. Lactoferrin prepared according to Querinjean et al. (21) was generously supplied by Jean-Paul Prieels, Universite Libre de Bruxelles. Human plasma $\alpha_{2} \mathbf{M}$ was purified by a modification (19) of the method of Kurecki et al. (22). All other reagents were the best commercial grade available.

Electrophoresis. Native polyacrylamide gel electrophoresis was performed on $5 \%$ slabs with the continuous Tris-borate system of Nelles et al. (23) or on $7.5 \%$ gels using the discontinuous buffer system of Davis (24). Gels were stained with Coomassie brilliant blue G-250.

Enzyme activity assays. SOD activity was measured according to the procedure of McCord and Fridovich (14). The ability of $\alpha_{2} \mathrm{M}$ to bind trypsin following reaction with PEG was studied with a modification of the method of Ganrot (28). A detailed description of the procedure is presented elsewhere (29). In other experiments, $\alpha_{2} \mathbf{M}$-trypsin complex was preformed and then reacted with activated PEG. BAPNA substrate was added and amidolytic activity was assayed.

Protein concentrations. The concentrations of unmodified proteins were calculated using the following extinction coefficients and molecular weight determinations: $\alpha_{2} \mathrm{M}$, $A_{1 \mathrm{~cm}, 280 \mathrm{~nm}}^{1 \%}=8.93, M_{\mathrm{r}}=718,000(25)$, lactoferrin, $A_{1}^{1 \%} \mathrm{~cm} .280 \mathrm{~nm}=10, M_{\mathrm{r}}=77,000(21)$, bovine copper-zinc SOD, $A_{1}^{1 \%} \mathrm{~cm}, 280 \mathrm{~nm}=2.70$, $M_{\mathrm{r}}=31,200(14,26)$. The concentration of PEG-modified protein was estimated by the 
Biuret procedure (27). The unmodified proteins served as standards.

Purification of bovine liver copper-zinc $S O D$. The procedure of McCord and Fridovich (14) for isolating SOD from bovine erythrocytes was modified for a bovine liver source. All steps were performed at $4^{\circ} \mathrm{C}$ unless otherwise specified. Fresh bovine liver $(900 \mathrm{~g})$ was homogenized in a Waring blender for $2 \mathrm{~min}$ in 2 liters of deionized water and then filtered through cheese cloth. Ethanol $(0.25 \mathrm{vol})$ and chloroform $(0.15 \mathrm{vol})$ were added with stirring and the mixture centrifuged $(9200 \mathrm{~g})$ for 30 min. To the supernatant, $300 \mathrm{~g} /$ liter of anhydrous $\mathrm{K}_{2} \mathrm{HPO}_{4}$ was added with stirring and the preparation was centrifuged for $20 \mathrm{~min}$ at $21,000 \mathrm{~g}$. The supernatant was placed in a separatory funnel and the upper ethanol phase was collected and centrifuged for $20 \mathrm{~min}$ at $21,000 \mathrm{~g}$. The supernatant was again placed in a separatory funnel to remove and discard residual lower phase. The upper ethanol phase containing SOD activity was rapidly cooled to between -2 and $-5^{\circ} \mathrm{C}$ in a salt-ice bath and $0.75 \mathrm{vol}$ of acetone at $-20^{\circ} \mathrm{C}$ were added with stirring. The mixture was immediately centrifuged $(21,000 \mathrm{~g})$ for $20 \mathrm{~min}$ and the precipitate collected and dispersed with a Tenbroek homogenizer in $100 \mathrm{~cm}^{3}$ cold deionized $\mathrm{H}_{2} \mathrm{O}$. Ammonium sulfate $(32.6 \mathrm{~g} / 100 \mathrm{ml})$ was added, the mixture centrifuged $(21,000 \mathrm{~g})$ for $20 \mathrm{~min}$, and the precipitate discarded. The supernatant was dialyzed against $2.5 \mathrm{mM} \mathrm{K} P_{1}$, pH 7.45 and applied to a DE-52 column (2.5 $\times 35 \mathrm{~cm}$ ) equilibrated in the same buffer at $4^{\circ} \mathrm{C}$. The column was eluted sequentially at pH 7.45 with $250 \mathrm{ml}$ each of $2.5 \mathrm{mM} \mathrm{K} P_{\mathrm{i}}$, and $10 \mathrm{mM} \mathrm{K} P_{\mathrm{i}}$ with $7 \mathrm{ml}$ fractions collected at $2 \mathrm{ml} / \mathrm{min}$. SOD eluted from the column at the $10 \mathrm{mM} \mathrm{K} P_{\mathrm{j}}$ step. Purity of the fractions was determined by polyacrylamide gel electrophoresis. Fractions containing purc SOD were pooled. Fractions containing significant amounts of impure SOD were pooled and rechromatographed on the same DE-52 column. The presence of two to three SOD isoenzymes was verified by comparison of gels stained for protein with gels stained for SOD activity (30). The purified SOD had a specific activity of 3200 units/mg using the activity assay of McCord and Fridovich (14) and a protein determination as described by Murphy and Kies (31).

Radioiodination of proteins. Proteins were radiolabeled by the solid state lactoperoxidase procedure of David and Reisfeld (32). The specific activities in $\mathrm{cpm} / \mu \mathrm{g}$ of the proteins were SOD, $1.3 \times 10^{4}$; lactoferrin, $5.7 \times 10^{4}$; and $\alpha_{2} \mathrm{M}, 5.5 \times 10^{5}$.

Activation of PEG. The PEG was dissolved in dioxane at $37^{\circ} \mathrm{C}$ at a concentration of 50 mM (PEG-2, PEG-4, and PEG-5) or $5 \mathrm{~mm}$ (PEG-20) and 1, 1'-carbonyldiimidazole added to a final concentration of $500 \mathrm{mM}$. The solution was incubated at $37^{\circ} \mathrm{C}$ for $2 \mathrm{~h}$ with stirring and then dialyzed extensively against $\mathrm{H}_{2} \mathrm{O}$ at $4^{\circ} \mathrm{C}$. The activated PEG-2, PEG-4, and PEG-5 solutions were dialyzed in Spectrapor dialysis membranes with 1000,2000 , and 3500 $M_{\mathrm{r}}$ inclusion limits, respectively, and the activated PEG-20 solution was dialyzed in a dialysis membrane with a $10,000 M_{\mathrm{r}}$ inclusion limit. The solutions were then lyopholized and stored dessicated at $4^{\circ} \mathrm{C}$. The resultant powder constituted "activated PEG."

Elemental analysis of activated PEG derivatives. Analysis for percent hydrogen, carbon, oxygen, and nitrogen content of the activated PEG derivalives was performed by Spang Microanalytical Laboratory (Eagle Harbor, Mich.).

TNBS titration studies. The percentage of SOD amino groups that reacted with the activated PEG was determined using the TNBS titration procedure described by Glazer et al. (33). Prior to the TNBS titration, the PEGSOD adducts were dialyzed in tubing with a $50,000 M_{\mathrm{r}}$ cutoff and concentrated in an Amicon ultrafiltration apparatus with an XM-50 membrane.

Coupling of activated PEG to proteins. Activated PEG-4 and $5(90 \mathrm{~mm})$ and radiolabeled SOD $\left(5 \times 10^{-5} \mathrm{M}\right)$ were incubated in 10 mM sodium borate, $\mathrm{pH} 8.5$, and $4{ }^{\circ} \mathrm{C}$ for 48 


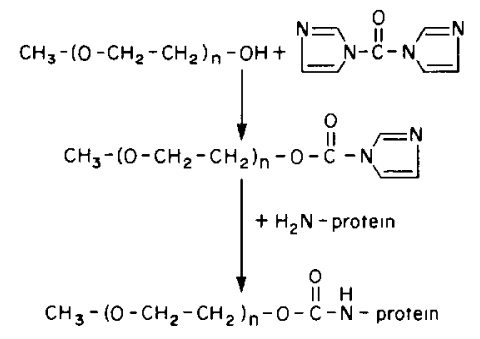

FIG. 1. Proposed mechanism for the formation of $1,1^{\prime}$ carbonyldiimidazole-activated monofunctional PEG and for the reaction of the activated PEG with amino groups of a protein.

h. At $48 \mathrm{~h}$, the concentration of activated PEG5 was increased to $180 \mathrm{mM}$ and the incubation continued for another $48 \mathrm{~h}$. In other studies, $180 \mathrm{mM}$ PEG-5 was present for the entire 96-h incubation.

Trypsin was incubated with radiolabeled $\alpha_{2} \mathrm{M}$ in $10 \mathrm{mM}$ sodium borate, $\mathrm{pH} 8.5$, for 5 min at room temperature at a trypsin to protease inhibitor ratio of 2. Activated PEG-2, PEG-4, and PEG-5 (40 mM) were incubated with $1 \times 10^{-6} \mathrm{M} \alpha_{2} \mathrm{M}$-trypsin complex in the same buffer for $72 \mathrm{~h}$. Activated PEG-20 (10 $\mathrm{mM}$ ) was incubated with $5 \times 10^{-7} \mathrm{M} \alpha_{2} \mathrm{M}-$ trypsin complex for $72 \mathrm{~h}$. Uncomplexed $\alpha_{2} \mathrm{M}$ was reacted with $P E G$ under similar conditions.

Activated PEG-2 or 4 (40 or $160 \mathrm{~mm}$ ) anc radiolabeled lactoferrin $\left(4 \times 10^{-6} \mathrm{M}\right)$ were incubated in $10 \mathrm{mM}$ sodium borate, $\mathrm{pH} 8.5$, at $4 \mathrm{C}^{\circ}$ for $72 \mathrm{~h}$.

Clearance studies. Clearance studies were performed in 20-week-old CD-1 female white mice as previously described $(19,34)$. Studies were generally performed in triplicate and the results averaged. Each individual study varied by less than $5 \%$ compared to the mean.

\section{RESULTS}

Elemental analysis of activated PEG derivatives. The expected product of the reaction of 1,1'-carbonyldiimidazole with the hydroxyl group of PEG is an imidazole carbamate derivative (13). Figure 1 illustrates the proposed structure of activated PEG formed by this procedure. The nitrogen content for each of the activated PEG derivatives was calculated using this general structure, and the predicted value compared to the actual content determined by elemental analysis of the activated PEG derivatives (Table 1). For each of the activated PEG derivatives, experimental nitrogen content was essentially identical to the calculated percent nitrogen from the structure of activated PEG in Fig. 1.

TNBS titration of the PEG derivatives of $S O D$. TNBS titration was performed to determine if amino groups of the PEG-derivatized protein were modified as predicted by the structure of the PEG-protein adduct given in Fig. 1. The PEG-4 and PEG-5 derivatives of SOD were extensively dialyzed in 50,000 $M_{\mathrm{r}}$ inclusion limits dialysis tubing and concentrated using a filtration membrane with a similar cutoff to remove $P E G$ which interferes with TNBS titration (data not shown). The TNBS titration results showed the PEG-4 derivative of SOD had $5 \%$ and the PEG-5 derivative $10 \%$ titratable amino groups as compared to the unmodified protein.

Gel electrophoresis of PEG modified SOD. Polyacrylamide gel electrophoresis was used to demonstrate that incubation of activated PEG with SOD produces an altered form of the enzyme and to study the effect of different incubation conditions on the formation of a PEG-SOD adduct. The effect of two different

TABLE 1

ELEMENTAL ANALYSIS OF ACTIVATED PEG DERIVATIVES

\begin{tabular}{cll}
\hline & \multicolumn{2}{c}{$\%$ Nitrogen } \\
\cline { 2 - 3 } Activated & Predicted & Found \\
\hline PEG & 1.3 & 1.1 \\
PEG-2 & 1.6 & 1.6 \\
PEG-4 & 0.55 & 0.44 \\
PEG-20 & 0.56 & 0.56 \\
\hline
\end{tabular}

Note. The \% nitrogen found is compared to the \% nitrogen predicted from the structures of activated PEG shown in Fig. 1. 
concentrations of activated PEG-5 on SOD derivitization is shown in Fig. 2. The nature of the PEG-protein adduct varies with the reaction conditions. Altered electrophoretic behavior probably reflects both decreased positive charge and increased size of the modificd protcin. The greater mobility electrophoretic bands in gels B, C, and D of Fig. 2 should represent unmodified and less highly modified protein.

Activity and clearance of PEG-modified $S O D$. The catalytic activity of SOD after modification with PEG-4 and PEG-5 was de-

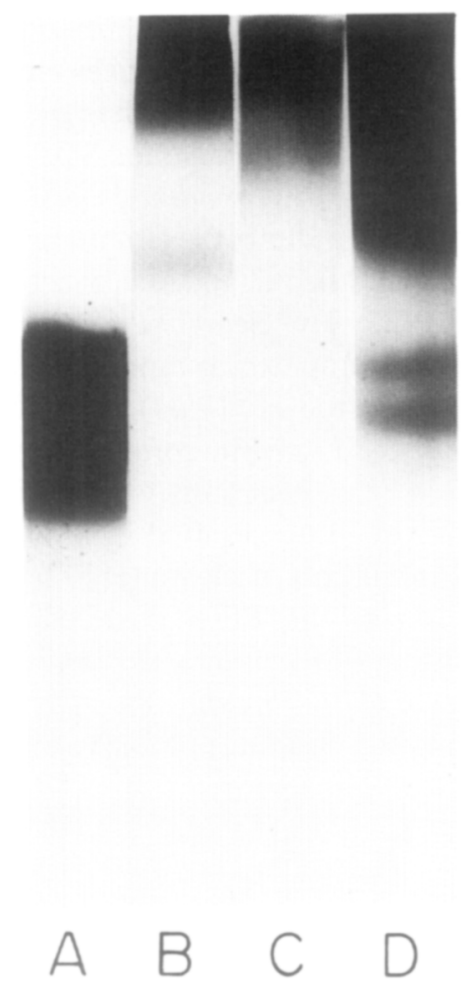

FIG. 2. Polyacrylamide gel electrophoresis under native conditions (24) of SOD and its PEG-5 derivative. Twenty micrograms of protein was applied to each gel lane. Gel A- unmodified SOD; gel B-SOD incubated with $90 \mathrm{~mm}$ activated PEG-5 for $48 \mathrm{~h}$; gel C-SOD incubated with 90 $\mathrm{mM}$ activated PEG-5 for $48 \mathrm{~h}$ at which time the concentration of PEG-5 was doubled and the incubation continued for another $48 \mathrm{~h}$; gel D-SOD incubated with 180 $\mathrm{mM}$ activated PEG-5 for $96 \mathrm{~h}$. The direction of migration is from top to bottom with bottom being the anode.

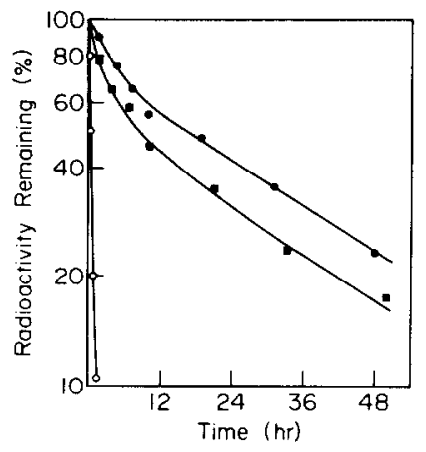

FIG. 3. Blood clearance in the mouse of SOD and its PEG derivatives. Graph shows the clearance of unmodified (O), PEG-5 (E), and the PEG-4-derivatized SOD (O).

termined. For both of these derivatives the enzyme retained greater than $95 \%$ of its activity. This compares to only $51 \%$ retention of enzymatic activity upon derivatization of SOD with cyanuric chloride activated PEG (8). The clearance of intravenously injected SOD and its PEG-4 and PEG-5 derivatives are shown in Fig. 3. Less than $15 \%$ of the native protein remained in the circulation 20 min after injection whereas approximately $20 \%$ of the PEG-5 derivative and $30 \%$ of the PEG-4 derivative remained in the circulation $40 \mathrm{~h}$ after injection. The apparent half-life of SOD was $3.5 \mathrm{~min}$ for the native protein, $9 \mathrm{~h}$ for the PEG-5 derivative, and $16.5 \mathrm{~h}$ for the PEG-4 derivative.

Activity of PEG-modified $\alpha_{2} M$ and $\alpha_{2} M-$ trypsin complex. The PEG-2, PEG-4, PEG-5, and PEG-20 derivatives of $\alpha_{2} \mathrm{M}$ demonstrated trypsin binding activities of $80,35,38$, and $63 \%$, respectively, as compared to the unmodified protein. This decrease in trypsin binding activity may result from steric hindrance in the interaction of the PEG-modified $\alpha_{2} \mathrm{M}$ with trypsin. There was, however, an increase in $\alpha_{2} \mathrm{M}$-trypsin amidolytic activity for each of the PEG derivatives of preformed $\alpha_{2} \mathrm{M}$-trypsin complex. For the PEG-2, PEG4, PEG-5, and PEG-20 derivatives of $\alpha_{2} \mathrm{M}-$ trypsin complex the amidolytic activity was $120,120,102$, and $270 \%$, respectively, of the 


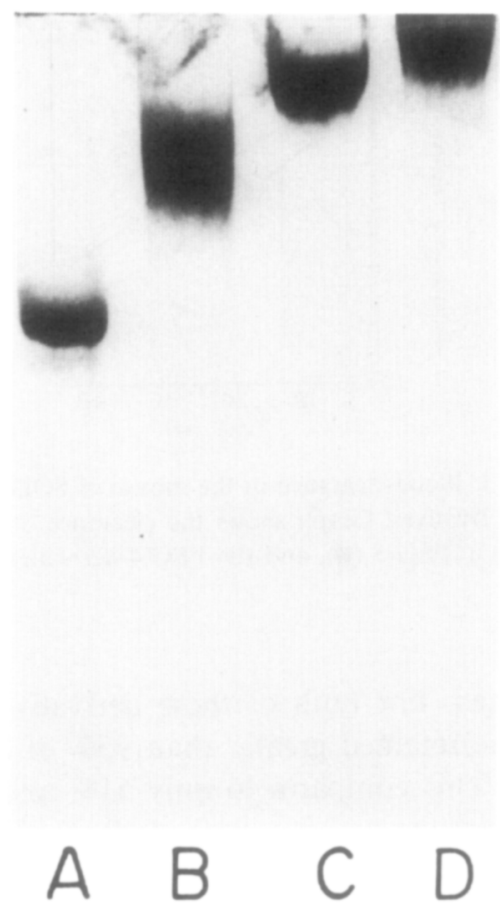

FIG. 4. Native polyacrylamide gel electrophoresis performed on 5\% slabs according to Nelles et al. (23) of $\alpha_{2} \mathrm{M}$ trypsin complex and its PEG derivatives. Five to seven micrograms of each protein sample was applied. Gel Aunmodified $\alpha_{2} \mathrm{M}$-trypsin complex; gel B-PEG-2 derivative; gel C-PEG-4 derivative; gel D-PEG-20 derivative. The direction of migration is from top to bottom with the bottom being the anode.

control value. In control experiments, unreacted PEG had no effect on the activity of $\alpha_{2} \mathrm{M}$-trypsin when added simultaneously with the substrate BAPNA. Trypsin amidolytic activity is increased after PEG derivatization using the cyanuric chloride procedure (35). The present results may represent a similar phenomenon.

Electrophoresis of PEG-modified $\alpha_{2} M-$ trypsin complex. Figure 4 shows a comparison between the electrophoretic mobilities in a native electrophoresis system of unmodified and PEG-modified $\alpha_{2} \mathrm{M}$-trypsin complex. The PEG derivatives of $\alpha_{2} \mathrm{M}$-trypsin complex distributed in a broader band than unmodified $\alpha_{2} \mathrm{M}$-trypsin suggesting some heterogeneity in the population of derivatives. The de-

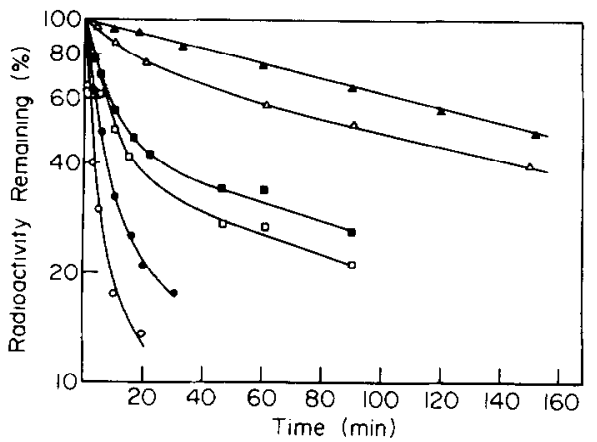

FIG. 5. Clearance of $\alpha_{2} M$-trypsin complex, and its PEG derivatives. The graph shows the clearance of unmodified $\alpha_{2}$ M-trypsin complex (O), PEG-2 (๑), PEG-4 (®), PEG$5(\square)$, and PEG-20-derivatized $\alpha_{2} \mathrm{M}-\mathrm{T}(\Delta)$. Native $\alpha_{2} \mathrm{M}$ (A) is shown for comparison.

creased mobilities of the derivatives most likely reflect decreased positive change and increased size as was the case for SOD.

Clearance of PEG-modified $\alpha_{2} M$-trypsin complex. Figure 5 shows the clearance of $\alpha_{2} \mathrm{M}-$ trypsin complex before and after reaction with activated PEG. The clearance of unmodified $\alpha_{2}$ M-trypsin complex was rapid in agreement with previous studies $(19,34)$. The PEG derivatives of $\alpha_{2} \mathrm{M}$-trypsin complex cleared at a decreased rate. Reactions with higher molecular weight PEGs resulted in a more pronounced inhibition of clearance. The apparent half-life of the PEG-20 derivative approached that of the unreacted inhibitor.

Clearance of PEG-modified lactoferrin. Figure 6 shows the clearance of native and PEG-

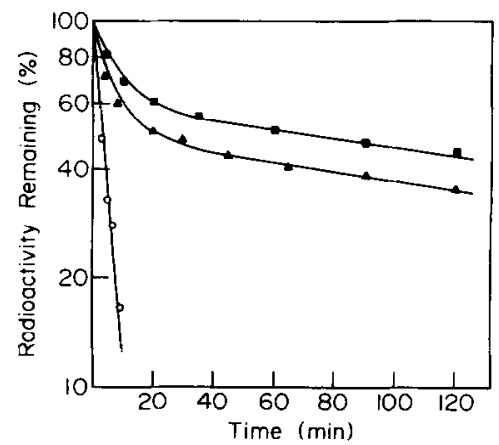

FIG. 6. Clearance of native and PEG modified lactoferrin. The graph shows clearances of unmodified $(O)$, PEG-2 (A), and PEG-4 derivatives of lactoferrin (a). 
modified lactoferrin. The half-life increased from less than $3 \mathrm{~min}$ for unmodified lactoferrin to $15 \mathrm{~min}$ for the PEG-2-modified protein and to $60 \mathrm{~min}$ for the PEG-4 derivative. Unlabeled native lactoferrin significantly competed for clearance with the PEG-2 derivative of radiolabeled lactoferrin. When a 3000 -fold molar excess of unlabeled native lactoferrin was injected with the radiolabeled derivative, the clearance of the derivative was prolonged fivefold. This result suggests that the derivatized protein clears on the same hepatocyte receptor that clears native lactoferrin (17). Lactoferrin precipitated when incubated with $40 \mathrm{mM}$ PEG-5 or greater than $160 \mathrm{mM}$ PEG-2 or PEG-4. Electrophoresis confirmed that the precipitates contained lactoferrin. Precipitated lactoferrin when redissolved cleared at a rate typical of the unmodified protein suggesting that no derivatization occurred. PEG is capable of precipitating many proteins without denaturation (36) and it appears likely that this phenomenon was observed under these reaction conditions.

\section{DISCUSSION}

Proteins are increasingly important in clinical medicine as drugs, but many of these proteins must be obtained from nonhuman sources since insufficient amounts can be purified from available human tissue or, for example, as in the case of streptokinase, the protein is not synthesized by eukaryotic organisms (see Ref. (34) for a discussion of the uses of streptokinase). This raises the problem of protein antigenicity. A second problem encountered when proteins are used as drugs is the short half-lives of many of these preparations. As an example, streptokinase has a half-life of only about $15 \mathrm{~min}$ (34).

Two interesting characteristics of some PEG-protein adducts, as comparcd to the unmodified proteins, are an increase in blood circulation time and a decrease in antigenicity and immunogenicity $(1,6)$. Unfortunately, the coupling of PEG to proteins often results in substantial loss of activity. The coupling of cyanuric chloride activated PEG to SOD results in an approximate loss of $50 \%$ of the activity. Modification of L-glutaminase-L-asparaginase results in loss of almost $90 \%$ of its activity $(6,10)$.

This report describes a new technique for linking PEG polymers to proteins by using an easily prepared carbonyldiimidazole-activated PEG. The formation and isolation of the activated PEG is a simple three-step procedure consisting of incubating carbonyldiimidazole with PEG in a nonaqueous solvent, dialyzing the product against water, and lyophilizing the preparation. The resultant "activated PEG" is an imidazole carbamate derivative of the hydroxyl group of the polymer as illustrated in Fig. 1 for a monofunctional PEG. Support for this proposed structure was obtained by elemental analysis.

The proteins derivatized with the activated polyethylene glycols were chosen to represent three different mechanisms of plasma clearance; namely, passive excretion (SOD), recognition of unique amino acid recognition sites by a receptor ( $\alpha_{2} \mathrm{M}$-trypsin), and carbohydrate recognition by receptors (lactoferrin) $(15,17,19)$. Two of these proteins have the additional advantage of possessing an enzyme activity (SOD) and a protease binding function $\left(\alpha_{2} \mathrm{M}\right)$, which can be evaluated after PEG modification. The antigenicity or immunogenicity of PEG adducts prepared by use of carbonyldiimidazole-activated PEG was not evaluated. These properties are not predictable a priori and must be evaluated for each PEG-protein adduct prepared by any of the reported coupling procedures.

When SOD was incubated with a 3600 -fold molar excess of activated PEG-4 or PEG-5. less than $10 \%$ of the free amino groups remained. This compares favorably with cyanuric chloride-activated PEG-5 derivatization of SOD (8). The PEG-4 adduct of SOD made with carbonyldiimidazole-activated PEG had greater than $95 \%$ of the activity of native SOD and a blood circulation half-life 
of $16 \mathrm{~h}$. The PEG adduct of SOD made with cyanuric chloride-activated PEG had a similar half-life, but as described above, retained only $51 \%$ catalytic activity (8).

There was also a striking change in the blood circulation half-life of lactoferrin after derivatization with carbonyldiimadazole activated PEG. Native lactoferrin competed for the clearance of a radiolabeled PEG-lactoferrin complex consistent with the clearance of the modified derivative by the same mechanism which clears the native protein, albeit at a slower rate.

The ability of PEG-modified $\alpha_{2} \mathrm{M}$ to bind trypsin was decreased significantly, presumably because of steric hindrance in the interaction of the PEG modified $\alpha_{2} \mathrm{M}$ with trypsin. PEG modification of preformed $\alpha_{2} \mathrm{M}$-trypsin, however, yielded derivatives which did not demonstrate loss of amidolytic activity. Clearance studies of $\alpha_{2} \mathrm{M}$-trypsin demonstrated that a relatively large polymer (PEG20) was necessary to cause an increase in the plasma half-life in contrast with the PEG derivatives of SOD and lactoferrin. The plasma clearance of PEG-20- $\alpha_{2} \mathrm{M}$-trypsin actually approached that of the native molecule.

The plasma clearances of the PEG adducts of SOD, lactoferrin, and $\alpha_{2} \mathrm{M}$-trypsin were generally biphasic while the clearances of the native ligands were essentially first order. This difference probably reflects some heterogeneity in the extent of protein modification. The comparisons, therefore, of the half-lives of modified and unmodified proteins is somewhat misleading since it tends to underestimate the actual increase in the circulating halflives of the modified proteins. This was particularly evident for the PEG derivatives of lactoferrin where the apparent half-life increased from about $3 \mathrm{~min}$ for the reactive molecule to $15 \mathrm{~min}$ (PEG-2) and $60 \mathrm{~min}$ (PEG-4), respectively. In each case, 50 to $75 \%$ of the modified protein population actually demonstrated a plasma clearance of several hours.

These studies document the utility of carbonyldiimidazole-activated PEG as a cou- pling reagent for proteins. This procedure offers a simplified approach for preparing such derivatives. The method may be particularly useful where other such procedures result in protein inactivation.

\section{ACKNOWLEDGMENTS}

This work was supported by Research Grant HL-24066 from the National Heart, Lung, and Blood Institute (S.V.P.), CA-29589 from the National Cancer Institute (S.V.P.), and a Veterans Administration Merit Review Grant (C.O.B.). S.L.G. is a Predoctoral Fellow, Medical Scientist Training Program (GM07171).

\section{REFERENCES}

1. Abuchowski, A., van Es, T., Palczuk, N. C., and Davis, F. F. (1977) J. Biol. Chem. 252, 3578-3581.

2. Lee, W. Y., and Sehon, A. H. (1977) Nature (London) 267, 618-619.

3. Matsushima, A., Nishimura, H., Ashihara, Y., Yokota, Y., and Inada, Y. Chem. Lett. (1980) 1980, $773-779$.

4. King, T. P., and Weiner, C. (1980) Int. J. Protein Peptide Res. 16, 147-155.

5. Lee, W. Y., and Schon, A. H. (1978) Immunol. Rev. 41, 200-247.

6. Abuchowski, A., McCoy, J. R., Palczuk, N. C., van Es, T., and Davis, N. C. (1977) J. Biol. Chem. 252, 3582-3586

7. Savoca, K. V., Abuchowski, A., van Es, T., Davis, F. F., Palczuk, N. C. (1979) Biochim. Biophys. Acta 578, 47-53.

8. Pyatak, P. S., Abuchowski, A., and Davis, F. F. (1980) Res. Commun. Chem. Pathol. Pharmacol. 29, $113-$ 127.

9. Chen, R. H.-L., Abuchowski, A., van Es, T., Palczk, N. C., and Davis, F. F. (1981) Biochim. Biophys. Acta 660, 293-298.

10. Abuchowski, A., van Es, T, Palczuk, N. C., McCoy, J. R., and Davis, F. F. (1979) Cancer Treatment Rep. 63, $1127-1132$.

11. Wieder, K. J., Palcquk, N. C., van Es, T., and Davis, F. F. (1979) J. Biol. Chem. 254, 12579-12587.

12. Davis, S., Abuchowski, A., Park, Y. K., and Davis, F. F. (1981) Clin. Exp. Immunol. 46, 649-652.

13. Bethell, G. S., Ayers, J. S., Hancock, W. S., and Hearn, M. T. W. (1979) J. Biol. Chem. 254, 2572-2574.

14. McCord, J. M., and Fridovich, I. (1969) J. Biol. Chem. 244, 6049-6055.

15. Petkrau, A., Chelack, W. S., Kelley, K., Barefoot, C., and Monasterski, L. (1976) Res. Commun. Chem. Pathol. Pharmacol. 15, 641-653.

16. Fantone, J. C., and Ward, P. A. (1982) Amer. J. Pathol. 107, 396-418. 
17. Prieels, J.-P., Pizzo, S. V., Glasgow, L. R., Paulson, J. C., and Hill, R. L. (1978) Proc. Nat. Acad. Sci. USA 75, 2215-2219.

18. Starkey, P. M., and Barrett, A. J. (1977) in Proteinases in Mammalian Cells and Tissue (Barrett, A. J., ed.), pp. 663-696, Elsevier, North-Holland Biomedical Press, Amsterdam.

19. Imber, M. J., and Pizzo, S. V. (1981) J. Biol. Chem. 256, 8134-8139.

20. Chase, T., Jr., and Shaw, E. (1970) in Methods in Enzymology (Perlmann, G. E., and Lorand, L., eds.), Vol. 19, pp. 20-27, Academic Press, New York.

21. Querinjean, P., Masson, P. L., Heremans, J. F. (1971) Eur. J. Biochem. 20, 420-425.

22. Kurecki, T., Kress, L. F., and Laskowski, M., Sr. (1979) Anal. Biochem. 99, 415-420.

23. Nelles, L. P., Hall, P. K., and Roberts, R. C. (1980) Biochim Biophys. Acta 623, 46-56.

24. Davis, B. J. (1964) Ann N. Y. Acad. Sci. 121, 404427.

25. Hall, P. K., and Roberts, R. C. (1978) Biochem. J. 171, 27-38.
26. Steinman, H. M., Naik, V. R., Abernethy, J. L., and Hill, R. L. (1974) J. Biol. Chem. 249, 7326-7338.

27. Goa, J. (1953) Scand. J. Clin. Lab. Invest. 5, 218 222.

28. Ganrot, P. O. (1966) Clin. Chem. Acta 14, 493-501.

29. Gonias, S. L., and Pizzo, S. V. (1981) J. Biol. Chem 256, 12,478-12,484.

30. Beauchamp, C., and Fridovich. I. (1971) Anal. Biochem. 44, 276-287.

31. Murphy, J. B., and Kies, M. W. (1960) Biochim. Biophys. Acta 45, 382-384.

32. David, G. S., and Reisfeld, R. A. (1974) Biochemistry 13, 1014-1021.

33. Glazer, A. N., DeLange, R. J., and Sigman, D. S. (1975) Chemical Modification of Proteins, pp. 7678, Amer. Elsevier, New York.

34. Gonias, S. L., Einarsson, M., and Pizzo, S. V. (1982) J. Clin. Invest. 70, 412-423.

35. Abuchowski, A., and Davis, F. F. (1979) Biochim. Biophy's. Acta 578, 41-46.

36. Polson, A., Potgieter, G. M., Largier, J. F., Mears, G. E. F., and Joubert, F. J. (1964) Biochim. Biophys. Acta 82, 463-475. 